\title{
El Doctor Ricardo Dávila Boza: Pionero de la infectología chilena. Higienista y salubrista
}

Enrique Laval R.

\section{Doctor Ricardo Davila Boza: Pioneer of infectious diseases specialists in Chile. Hygienist and public health expert}

Dr. Ricardo Dávila Boza (1850 -1937) was a man whose personality had no duplicities, "blunt and kind, with clear and defined convictions." With an illuminated vision and untiring tenacity, he published all sorts of written work: scientific, literary and poetic. He was always ready to defend his ideas but tolerant to other's. This article reviews his work in the hospitals "San José" and "San Juan" in Santiago. He studied the clinical aspects and epidemiology of infectious diseases becoming one of the famous physicians who collaborated in public health from 1870 to 1910. During 21 years he was head of the former Public Hygiene Institute. His work during the bubonic plague and smallpox epidemics on the second half of the nineteenth and the first years of the twentieth centuries was intelligent and shrewd. He was born in La Serena. Later he went back to the north of his country, to Freirina and Copiapó, starting his professional work.

Key words: Infectious diseases, epidemics, public health, Hygiene Institut.

Palabras clave: Enfermedades infecciosas, epidemias, salubridad, Instituto de Higiene.
Pontificia Universidad Católica de Chile

Facultad de Medicina Programa de Estudios Médicos y Humanísticos

Recibido: 26 agosto 2008 Aceptado: 2 septiembre 2008

\section{Correspondencia a:}

Enrique Laval Román revinf@sochinf.cl
Datos biográficos. Iniciación de actividad profesional. "Memorias" de Freirina y Copiapó.

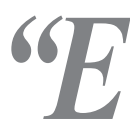
ntre los médicos cuyo nombre yace olvidado a pesar de sus muchos merecimientos, se encuentra el doctor Ricardo Dávila Boza, uno de los primeros que en Chile se dedicó al estudio clínico y epidemiológico de las enfermedades infecciosas". Con el correr del tiempo, abandonaría la clínica y se transformaría en un distinguido higienista, salubrista e ilustre director del antiguo Instituto de Higiene de Santiago ${ }^{1}$.

Había nacido en La Serena, en 1850, donde realizó sus estudios primarios, terminando los secundarios en el Instituto Nacional de Santiago, iniciando en 1869, los de Medicina, durante los cuales destacó por su dedicación y perseverancia, cumpliendo en forma sobresaliente como disector de Anatomía. Junto con el doctor Isaac Ugarte Gutiérrez, fue uno de los mejores alumnos de la Cátedra de Clínica Médica del profesor Germán Schneider, 1873-74.

Obtuvo su título profesional el día 7 de octubre de 1875 , accediendo previamente a la licenciatura con su tesis "Apuntes sobre el movimiento interno de la población en Chile y sobre las principales circunstancias

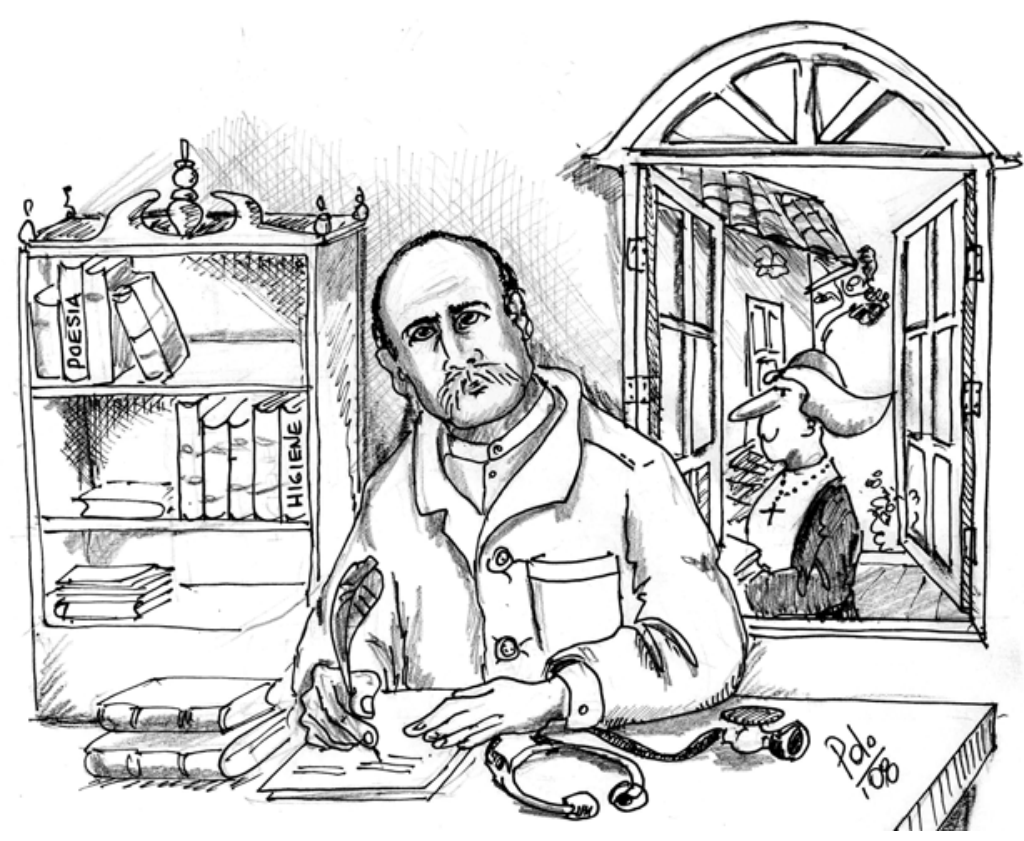

www.sochinf.cl 


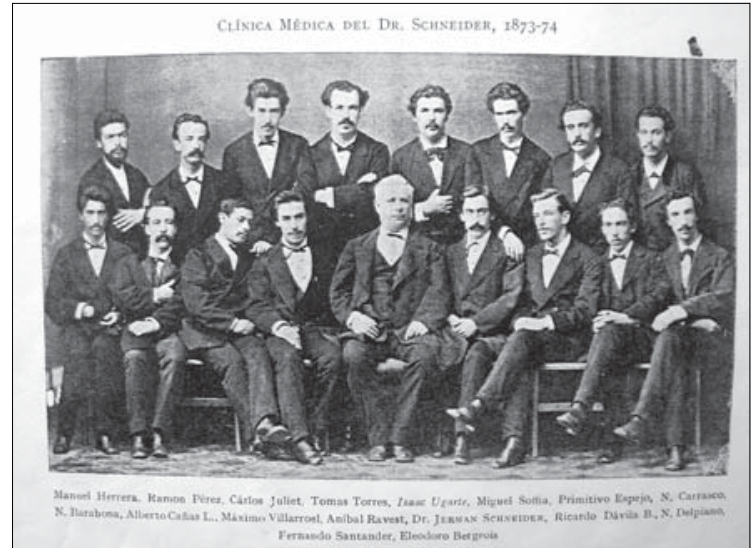

Figura 1. Clínica médica del Dr. Schneider. 1873-1874.

que tienen sobre él una notable influencia”, en la cual ya manifiesta su inquietud por la demografía, siendo publicada en Revista Médica de Chile de 1873 y en Anales de la Universidad de Chile (1875).

Comenzó la actividad profesional el $1^{\circ}$ de diciembre de 1875 , cuando fue designado "médico de ciudad" en Freirina, a cargo del hospital de dicha localidad durante cuatro años, hasta el 31 de diciembre de 1879, en que se traslada a Copiapó. Ahí ejerció la medicina en forma privada, pero en 1886 ingresó al hospital de la ciudad. Desde octubre de 1888 hasta fines de febrero de 1890 se desempeñó como "médico de vacuna" de Copiapó, Chañaral y Caldera ${ }^{1-3}$.

Durante su permanencia en Freirina y luego en Copiapó, escribió unas "Memorias", sobre climatología, sismología, morbi-mortalidad, etc. de la región, que fueron publicadas en Revista Médica de Chile, con el título de Revista Médica de Freirina y de Copiapó, respectivamente ${ }^{4,5}$. En la de Freirina (1877) dice que "las lluvias habidas han sido tres, pero tan insignificantes, que apenas han excedido a las del año anterior. Sin embargo, bastaron para levantar una vegetación y hacer concebir muy risueñas esperanzas para la agricultura, pero se marchitaron $y$ murieron con los primeros soles de septiembre".

Respecto de los temblores "notados desde Antofagasta a Valparaíso, se han hecho sentir también en Freirina, con toda su intensidad seguidos algunos de perturbaciones atmosféricas".

En cuanto a la "fisonomía médica de que me ocupo -relata el doctor Dávila- no ha habido rasgos notables. Las enfermedades catarrales han sobrepujado con mucho a las de carácter inflamatorio. Corizas, bronquitis y anginas catarrales, predominaron como pequeñas epidemias, sobre los males gástricos y tifoideas ligeras". En el otoño "perdi tres enfermos de meningitis: un joven de 15 años afectado desde la

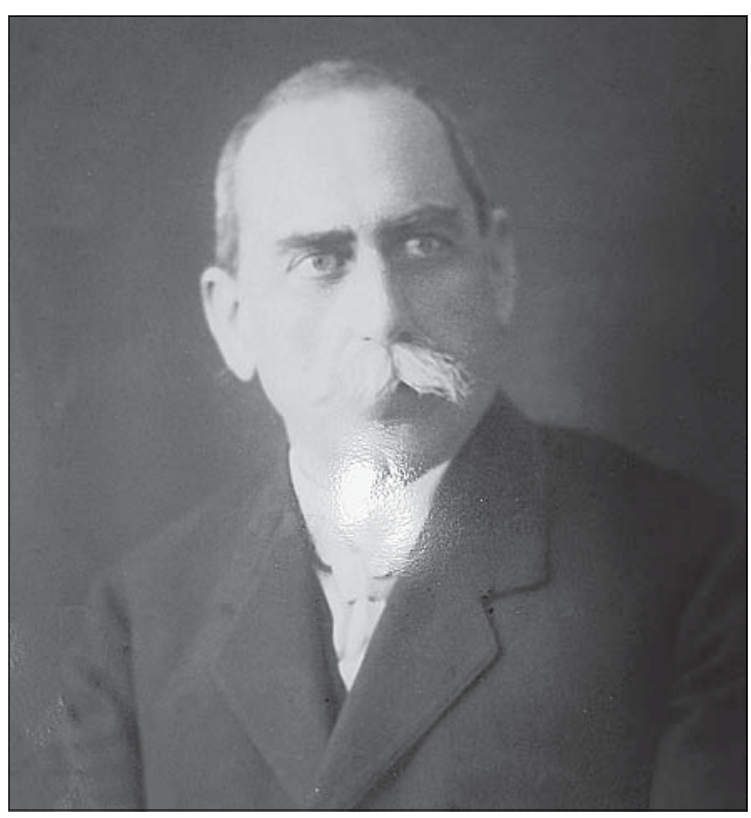

Figura 2. Ricardo Dávila Boza (1850-1937).

infancia de otitis interna, que sucumbió a una inflamación de la duramadre; una chiquilla de 11 años que murió al cuarto día de una meningitis de la base y un niñito de 5 años por una meningitis granulosa". Lo único notable -continúa- es la causa que ha producido el último, la frecuencia de darse lo que los niños llaman "vueltas de carnero", admitiendo que no había otros antecedentes.

Al cabo de un año en Copiapó (1879), expone "que un solo año de residencia en esta ciudad no ha permitido formarme una idea exacta de su clínica y patología", limitándose a presentar sólo una reseña. "Le ha llamado la atención la frecuencia de las afecciones orgánicas y funcionales del aparato cardiovascular y de diversas dispepsias". Piensa que las causas "son el uso muy extendido de los licores espirituosos, que felizmente tienden a ser sustituidos por la cerveza y vinos; las altas temperaturas, sequedad atmosférica y las rudas tareas de la minería".

"La tisis pulmonar, es inmensamente menos frecuente que en otras ciudades de Chile, asegurando que su mortalidad es menor de la que se observa en el pais".

"Los catarros respiratorios son frecuentes, de corta duración, por las influencias climáticas". También le ha asombrado "la falta de reumatismos agudos, sobre todo articulares. Las afecciones reumáticas, formas muy ligeras de reumatismo muscular y algunas neuralgias, han cedido con el yoduro de potasio, sulfato de quinina y revulsivos". 
"Las enfermedades del higado son escasas y no he visto casos de supuración hepática", cuya explicación atribuye a las cualidades salinas del agua de uso diario.

"La coqueluche, sarampión y viruela tuvieron carácter epidémico. Si ocasionaron muchas defunciones, se debió a la ignorancia, pobreza e indiferencia inexplicable de nuestros hombres de gobierno".

Completa sus observaciones anotando "que los medicamentos son muy caros y por la facilidad de ganarse la vida, las clases trabajadoras, poco previsoras. La única 'dispensaría' que hay presta servicios casi nulos, por estar situada muy distante de la población".

Es interesante recordar que cuando el doctor Dávila Boza se encontraba ejerciendo en Copiapó, los doctores don José Joaquín Aguirre y don Francisco Puelma Tupper, publicaron en 1883 en Revista Médica de Chile su trabajo sobre "Exhumación de cadáveres y ceremonias de cuerpo presente", donde se muestran partidarios de un entierro rápido para evitar contaminaciones, que provocó gran revuelo y estupefacción en aquella época e indujo al Gobierno del Presidente Domingo Santa María a prohibir las misas de cuerpo presente en las iglesias. El doctor Ricardo Dávila Boza, en un artículo publicado el año 1884, en la revista La Lectura de Santiago y con el título de "Los cadáveres considerados desde los puntos de vista higiénico y social", desvirtuó completamente y en forma muy razonada los argumentos vertidos por los doctores Aguirre y Puelma Tupper, demostrando que la infección postmorten "era muy relativa". Sin embargo, no hubo modificación de lo acordado por el Gobierno ${ }^{6,7}$.

\section{Médico del Lazareto San José (1891-1900)}

Un Decreto Supremo cursado en febrero de 1891, lo designó médico del Lazareto San José, confiándole la sección mujeres del Servicio de enfermedades infectocontagiosas agudas del establecimiento. La de hombres permaneció a cargo del doctor Luis Alberto Figueroa.

Al presentar a la Administración del Lazareto San José (a partir de 1897, Hospital San José), la Memoria de su servicio correspondiente a 1891, expresó con franqueza y precisión el estado en que se encontraba: "debo manifestar antes que todo, que cuando me hice cargo del lazareto, en los primeros días de febrero, estaba el establecimiento en tal estado de incuria, abandono, desaseo e inmundicia, que la primera idea que me sugirió su visita fue que probablemente ni entre los canes ni entre los hotentotes se vería indiferencia semejante por los padecimientos de seres humanos. Por no parecer exagerado renuncio a toda descripción. Básteme sólo recordar que los colchones eran simples montones de paja medio ensacada que probablemente no se habia renovado en muchos meses y no cuidando de mantener convenientemente repartida en toda la extensión del lecho, por lo cual la cama era un verdadero tormento para el enfermo, en lugar de procurarle alivio y descanso".

Esta triste situación tuvo pronto arreglo porque en el curso de 1891, las Hermanas de la Caridad pasaron a prestar sus servicios a San José. Tuvo la suerte el doctor Dávila Boza, durante todo su quehacer hospitalario, de contar a su lado con Sor Vicenta Rondizzoni, abnegada Hermana de la Caridad $^{3,8}$.

De acuerdo con lo manifestado por don Mariano Bascuñan Guerrero, el Hospital San José "es un hospital de infecciosos, aunque ni su ubicación, disposición y distribución de sus salas llenen las condiciones de un establecimiento de esa clase". Hay que señalar que las primeras salas fueron construidas en 1887, debido a la epidemia de cólera. Convertido más tarde en lazareto de variolosos, recibió también pacientes con diversas enfermedades infecciosas (tifus exantemático, escarlatina, erisipela, etc) y desde 1897 , tuberculosos ${ }^{8,9}$.

En 1891, prestó además sus servicios en el Dispensario El Carmen (calle Esmeralda) de la Junta de Beneficencia y en 1893 fue médico de la Hermandad de Dolores $^{1,3}$

El $1^{\circ}$ de enero de 1892 se puso término a los servicios del doctor Ricardo Dávila Boza en el San José, aparentemente por motivos políticos derivados de la Revolución de 1891. A pesar de esto, reingresó al nosocomio en octubre de dicho año. En esa época, cada uno de los dos médicos, Figueroa y Dávila, tenía cien camas a su cargo, con una renta de sesenta pesos mensuales.

Sin lugar a dudas, las deficiencias anotadas a su ingreso en 1891, debieron ser motivo de atención preferente de la Administración, pues en el informe anual, correspondiente a 1893 dice: "lo que queda por hacer no es mucho ni de gran urgencia, pero es conveniente no olvidarlo". Se refería a la necesidad de dotar al lazareto con una estufa de desinfección para la ropa de los variolosos.

Desde 1893, quedó como único médico el doctor Dávila, pero en 1896 se le designó como ayudante transitorio al estudiante de Medicina don Francisco Navarro, quien ese año obtuvo su título profesional. En abril de 1896 estalló en Santiago una epidemia de difteria y fue necesario habilitar las salas San Luis y Santa Filomena para recibir enfermos que no encontraban cabida en otros hospitales. Entre mayo y octubre se atendieron 107 enfermos de difteria, falleciendo $33^{8}$ 
Médico del Hospital San Juan de Dios (1901-¿1916?) Médico Inspector del Consejo Superior de Higiene (1899-1904). Director del Instituto Superior de Higiene (1904-1925). Reseña sobre Organismos de Salubridad desde la Colonia hasta la era Republicana (Siglo XIX)

El doctor Ricardo Dávila Boza empezó a trabajar a partir de 1901, en el Hospital San Juan de Dios, atendiendo durante una primera etapa enfermos tuberculosos. En julio de 1894 se acordó instalar un servicio especial para enfermos infecto-contagiosos agudos, dotado de tres pequeñas salas recién construidas, con una capacidad de 21 camas y tuvo la oportunidad de desempeñarse como médico tratante, permaneciendo en el Hospital San Juan de Dios algo más de 15 años ${ }^{1,10}$.

En el mes de diciembre de 1899 ya fue nombrado médico inspector del Consejo Superior de Higiene Pública, realizando esta función hasta el 10 de mayo de 1904, porque el día 11 pasó a reemplazar al doctor Alejandro del Río en la Dirección del Instituto de Higiene, conservando la jefatura de Higiene y Demografía, encargándose de la dirección de la Revista Chilena de Higiene que había fundado el Consejo y de la supervigilancia del Boletín de Higiene y Demografía ${ }^{1}$.

Naturalmente que estas nuevas actividades lo llevarían a disminuir en forma importante y progresiva sus labores asistenciales en el Hospital San Juan de Dios, hasta abandonarlas totalmente, para transformarse en un "prestigioso higienista".

Considero conveniente mencionar en las líneas que siguen lo que existió en el país en materia de salubridad, desde los tiempos coloniales hasta que el doctor Dávila asumió sus nuevas funciones.

El Protomedicato había nacido en España en el siglo $\mathrm{XV}$, como tribunal encargado de autorizar, controlar y aplicar medidas punitivas en el ejercicio de las profesiones médicas, asesorando al Gobierno, en lo concerniente a la salubridad. Incorporado a los países americanos exactamente con el mismo carácter, sobrevivió en la mayoría, hasta la era republicana y poco a poco fueron cercenándosele atribuciones, extinguiéndose completamente.

La Gobernación y la Capitanía General de Chile, dependían del virreinato del Perú y las funciones sanitarias, del Protomedicato de Lima. Por la distancia a que éste se encontraba, le impidió hacer sentir su acción en Chile y el Cabildo continuó utilizando las facultades que las leyes habían confiado a aquél.

El establecimiento de la Universidad de San Felipe con su Cátedra de Prima de Medicina, hizo recaer reglamentariamente en 1756 la designación de Protomé- dico, en su profesor el doctor Domingo Nevin y sus sucesores.

Pero todas las medidas adoptadas, ya sea por el Cabildo o el Protomedicato, no fueron capaces de influir en lograr un estado sanitario medianamente satisfactorio, pues el país vivía permanentemente diezmado por la viruela y el tifus exantemático.

En octubre de 1808 el Gobierno creó la Junta Central de Vacuna, que estuvo en funciones hasta la dictación del primer Código Sanitario de Chile, en 1918.

El 19 de noviembre de 1842 se fundó la Universidad de Chile y su Facultad de Medicina quedó encargada por ley "velar por el cultivo y adelantamiento de las ciencias médicas, dedicarse especialmente al estudio de las enfermedades endémicas y epidémicas de Chile, que afligen con frecuencia a la población, dando a conocer los medios preservativos y curativos, dirigiendo sus observaciones a la mejoría de la higiene pública y doméstica", atribuciones que pertenecían al Protomedicato, el que fue perdiendo su fisonomía de tribunal y el cargo de Protomédico vino a confundirse con el de Decano de la Facultad de Medicina de la Universidad de Chile.

El 30 de diciembre de 1886 entró en vigencia la ley de Policía Sanitaria (que entre otras cosas podía declarar cerrados los puertos marítimos y terrestres en casos de epidemias en países extranjeros, agregando numerosas disposiciones relativas a clausuras de puertos y cuarentenas, cordones sanitarios, denuncias de enfermedades contagiosas, aislamiento para evitar contaminaciones, desinfección pública, etc).

Los nuevos conceptos bacteriológicos y epidemiológicos hicieron absurda la existencia de cordones sanitarios e ilusa la inmensa mayoría de sus disposiciones.

En enero de 1887 el Gobierno dictó la Ordenanza General de Salubridad, mediante la cual se creó una Junta General asesora en materia de salubridad pública.

Pocos años después, el 15 de septiembre de 1892 , se promulgó la ley que creó el Servicio y el Consejo Superior de Higiene Pública, en reemplazo de la anterior Junta de Salubridad y fundó además el Instituto de Higiene, con un Consejo que no llegaba más allá de simples funciones asesoras, sin atribuciones ejecutivas. El Instituto de Higiene constaba de cinco secciones: higiene y estadística, química, microscopia y bacteriología, serología y desinfectorio público.

Por Decreto Supremo del 10 de diciembre de 1892 se crearon Consejos Departamentales de Higiene en todas las cabeceras o capitales de departamentos, dependientes del Ministerio del Interior.

En 1908 en un detallado informe sobre estos Consejos Departamentales, el doctor Ricardo Dávila Boza, se lamenta "que no han correspondido a las expectativas que se tuvieron presentes en su creación, con 
excepción del Consejo de Valparaíso, que supo mantenerse vivo y activo, haciendo sentir su influencia en todas las circunstancias en que ha sido necesario. También son acreedores de ser recordados los de Antofagasta, Talca y Concepción, porque en situaciones difíciles no han esquivado su patriótica cooperación a los gobernantes ni sus benéficos consejos a los vecindarios" ${ }^{11,12}$.

El doctor Dávila Boza estuvo a cargo de la dirección del Instituto de Higiene hasta su jubilación en junio de 1925, dando a conocer la vasta experiencia adquirida durante las epidemias en que le tocó actuar. Sus trabajos se publicaron casi exclusivamente en Revista Chilena de Higiene y Revista Médica de Chile, en la que también fue director desde 1907 a 1910.

Si bien preocupación primordial suya fue la profilaxis y la erradicación posible de las enfermedades infecciosas reinantes en Chile, el mayor empeño lo prodigó en las epidemias de peste bubónica y viruela, con notable inteligencia y sagacidad.

\section{Epidemias de peste bubónica (1903 y 1904)}

A fines de 1899, hizo su aparición, por primera vez en América del Sur, la peste bubónica. La epidemia se inició en Asunción y en Santos, extendiéndose rápidamente a Río de Janeiro y a las ciudades argentinas de Rosario, Santa Fe y Buenos Aires. El Gobierno de Chile envió una comisión médica a la República Argentina presidida por el doctor Alejandro del Río, en la cual participó el doctor Ricardo Dávila Boza, para estudiar el origen, marcha y características.

En mayo de 1903 estalló en Iquique una epidemia, cuyo estudio anátomo-clínico y epidemiológico permitió confirmarla como peste bubónica, sin conexión aparente con lo sucedido en Paraguay, Brasil y Argentina, sino que con ratas pestosas que llegaron en barco, provenientes del Callao (Perú). El 29 de ese mes, el Ministerio del Interior designó una comisión también presidida por el doctor Alejandro del Río e integrada por los médicos Ricardo Dávila Boza, Ramón Zegers y Luis Montero.

Destacada actuación le cupo al doctor Dávila, en las campañas efectuadas, en diversas zonas, ya que aparecieron focos en Arica, Valparaíso, Viña del Mar y Santiago, a tal punto que evacuó un informe "sobre la posible ubicación de un lazareto para pestosos en la capital". En marzo de 1904, la enfermedad fue nuevamente introducida en el país, procedente ahora desde la India, en un buque llegado a Antofagasta. En esta ciudad sucedió igual que en Iquique: los primeros casos pasaron inadvertidos, con invasión de Pisagua, Tocopilla, Mejillones, Taltal, Chañaral y Coquimbo.
A pesar de una notificación incompleta, se estimó que el total de enfermos, entre 1903 y 1910, habría alcanzado a 2.279, contabilizándose 382 fallecidos $(16,8 \%)^{13-17}$.

\section{Epidemias de viruela (1890-1892 y 1902-1913)}

En 1893, afirmaba Dávila Boza “que no habrá en el país un solo habitante que ignore que la viruela es la plaga que nos ha arrebatado quizás mayor número de vidas en todos los tiempos y que con tanta pertinacia se ha aclimatado en toda la extensión de nuestro territorio, que debemos considerarla, sin hipérbole, como nuestra plaga nacional y enfermedad propia característica"17.

Para manifestar en toda su intensidad "la alta proporción con que la viruela contribuye a aumentar la cifra de mortalidad general del país, sería necesario exponer su historia completa durante una larga serie de años, pero como esto -considera el doctor Dávilademandaría mayor tiempo del que dispone, se limita a un resumen del movimiento habido en los últimos tres años (1890, 91 y 92) en el Lazareto San José, único permanente de la capital, lo que bastará para llamar la atención sobre la materia con el fin de obligar a nuestros hombres de Gobierno a hacer alguna vez algo en esta causa, primordial de la salubridad pública y que servirá para deslindar bien claramente el campo de las respectivas responsabilidades, entre los que todo lo pueden y nada hacen y los que nada podemos y todo lo quisiéramos hacer".

En resumen: entre 1890 y 1892, ingresaron al lazareto permanente de Santiago, 4.859 variolosos, falleciendo 2.688 , o sea, el $55,3 \%$.

Concluye que "durante estos tres años continuos, la viruela se ha mantenido invariable en Santiago, con dos o tres víctimas diarias entre los desvalidos que han ido a ocupar un lecho en el Lazareto San José. Si a esto se agrega los que se han curado en sus casas y los que en los últimos meses ingresaron al Lazareto accidental del Salvador, la cifra de las victimas tendría que multiplicarse". El que cinco o seis defunciones día a día por la viruela durante tres años consecutivos se produzcan sólo dentro de Santiago, lleva al "ilustre higienista” a preguntarse: “ ¿no debería ser un motivo justísimo de alarma y de rubor para nuestro patriotismo y para el grado de cultura y de progreso que hemos alcanzado?".

La admonición con que termina el doctor Dávila es impactante: “QQuieran nuestros gobernantes, sus inspiradores y consejeros pesar la responsabilidad que les toca en tan delicada materia!"18.

En seguida, analiza las epidemias de viruela que se 
produjeron en los años 1902, 1903 y 1904. En el primero la enfermedad comprometió a Calama y Antofagasta, lo mismo que en 1903, pero afectando además la Pampa y Tocopilla, llegando a Arica, La Serena, Santiago, San Fernando y Copiapó.

Las defunciones ocasionadas por la enfermedad en estos tres años, alcanzaron a 2.107 personas, variando desde 35 en 1902 a 1.676 en 1904.

Con gran prolijidad y exactitud, señaló la marcha asumida por la epidemia en el curso de los años 1902 a 1904, desde el día de su importación de las provincias limítrofes de Bolivia al remoto extremo de la República y al no ser detenida al comienzo en los primeros puntos, se propagó con paso firme y seguro, a la mayor parte del territorio nacional ${ }^{19}$.

En junio de 1914 el doctor Ricardo Dávila Boza, escribía sobre la "Situación sanitaria del país", manifestando que en el "capitulo de las enfermedades evitables conviene detenerse un momento en aquellas que lo son casi en absoluto y que por esto no figuran ya en los cuadros nosológicos de las naciones civilizadas, pero que en Chile presentan un gran papel".

La viruela importada, al país desde los primeros días de la Conquista, hizo grandes estragos, tanto entre los conquistadores, como entre la población indígena durante todo el período colonial. Después de la introducción de la vacuna y obligatoriedad en 1887, las devastaciones disminuyeron un poco en frecuencia y en intensidad, manteniéndose endémica, sin dejar de contribuir a la morbilidad casi en ningún año, hasta en 1892-1893, época en que como se señaló, hubo una gran epidemia. Se creyó que la viruela había sido extinguida como consecuencia de la mayor propagación de la vacunación. En algunos casos que se presentaron en los puertos del sur, se comprobó que eran de inmigrantes recién llegados, no produciéndose nuevos, sin duda debido a las medidas que se arbitraron con este motivo de aislamiento de los enfermos y difusión de la vacuna.

A fines de 1912, hubo algunos casos en Calama; eran individuos procedentes de Bolivia, en cuyas provincias limítrofes la viruela era endémica. Esto dio lugar a una epidemia local, que no se extendió debido a las medidas de hospitalización y aislamiento, desinfección de los domicilios y vacunación en masa de la población. Pasaron algunos meses sin que se presentaran nuevos casos, pero por desgracia aparecieron algunos individuos enfermos o en período de incubación y, una vez más, se produjo la invasión a todo el país agregando Dávila Boza "que aún subsiste en varias partes". Debe estimarse que la epidemia iniciada en Calama en 1902, así como los casos que se presentaron nuevamente en aquella región, con exten- sión a casi todo el país, constituye la gran epidemia de viruela de 1902 a 1913 habida en Chile. En el lapso de estos 12 años, se produjo un total de 30.967 defunciones, reconocidas y comprobadas, correspondiendo 10.178 (un tercio) al año 1905. Según Dávila Boza el total de fallecidos debería aumentarse por lo menos en $25 \%$ por los numerosos enfermos "que se ocultan y se asisten en sus casas sin médico, por temor a que sean declarados y obligados a hospitalizarse", lo que autorizaría a afirmar "que las defunciones producidas por la epidemia y extendida progresivamente a todo el país, reina aún en varias de sus provincias, sobrepasando seguramente los 40.000 individuos".

Finalmente estima "que la epidemia de viruela pudo evitarse con la sola adopción o realización de la sencillísima medida propuesta por el Consejo de Higiene en marzo de 1903, es decir, en los primeros momentos de la epidemia establecer en Antofagasta, con ramificación en Calama, una inspección y estación sanitaria dotada de todos los elementos necesarios para atender cualquier peligro que amenazase a las diferentes poblaciones de la provincia, principalmente por el lado de Calama y de la frontera bolivia$n a " 17$.

Sociedad Protectora de la Infancia y posibilidad de un hospital de niños en Valparaíso

En el Editorial de Revista Médica de Chile, de octubre de 1893, el doctor Dávila Boza, escribe que "don Vicente Santa Cruz, y don Marcelo A. Mena han firmado una escritura de promesa de compra venta de la conocida Quinta de Mena, situada en el cerro Florida de Valparaíso y que se destina a establecimiento central de los servicios que tomará a su cargo la Sociedad Protectora de la Infancia, fundada alli hace algunos años".

Esa propiedad -dice- "se transformará en un hermoso Hospital de Niños, que correrá a cargo de un médico que resida en el establecimiento y que se ocupe exclusivamente de todo lo que se refiere a la salud e higiene de los niños".

No es extraño lo publicado por el doctor Ricardo Dávila Boza, porque uno de sus anhelos más caros fue el que se crearan en Chile hospitales para niños, formando opinión, tanto en el pueblo como a nivel legislativo, para la construcción de aquéllos.

Resalta en su escrito que la Sociedad Protectora de la Infancia de Valparaíso, abrirá "desde luego un dispensario para dar alimentación a las madres que crian a sus hijos y a los niños que languidecen por falta de alimentación conveniente".

Sabido es que la mortalidad de los niños alcanza en 
Santiago y en Valparaíso "proporciones aterradoras, que nadie podría prever y que no encuentran explicación alguna en las condiciones climáticas o telúricas tan benignas de nuestro país. Por lo cual se hace necesario suponer que hay entre los hábitos y costumbres de nuestro pueblo algunos vicios y resabios de gran trascendencia, perjudiciales para la salud de los niños, a los cuales hay que atribuir la excesiva mortalidad de estos".

A los constantes desvelos del doctor Dávila Boza se debió, en no poca parte, la creación del primer Hospital de Niños de Santiago ${ }^{3,20}$.

\section{Otras actividades. Su labor poética y literaria. Bosquejo de su carácter}

Entre las muchas otras actividades desarrolladas por el doctor Ricardo Dávila Boza, se podría señalar que fue fundador de la Liga contra la Tuberculosis, dirigiendo en compañía del doctor Pedro Lautaro Ferrer en 1909, "El Heraldo de Alianza Social", órgano oficial de dicha Liga. Durante 1912 y en el período 1914-1915 fue presidente de aquélla y a su iniciativa se debió la creación del Sanatorio Marítimo de Cartagena y de otro en San José de Maipo.

También trabajó con tesón por la promulgación en 1918 del Código Sanitario que dormía en las Cámaras más de cinco años, contribuyendo a su aprobación, gracias a la labor parlamentaria del recordado doctor Ramón Corbalán Melgarejo ${ }^{1,3}$.

Junto con la actividad científica, la literatura y la poesía motivaron al doctor Dávila Boza. Conociendo la psicología popular a través de su diario contacto con los pacientes y familiares, escribió en 1887, la novela "Mercedes", publicada en la Revista de Artes y Letras, siendo recibida con elogios por la crítica. ${ }^{1,3,21}$

La obra poética que reúne "como exquisito ramillete de poesías y que bajo el nombre de "Azahares" fue el más bello regalo que dedicó a su esposa doña Delia Budge, con quien contrajo matrimonio el 2 de abril de 1885 en Copiapó, termina su poema principal así:

" $Y$ con estos versos que el amor me dicta. $y$ al correr de la pluma son escritos aunque digan lo que otros ya dijeron son sincera expresión de mi cariño" ${ }^{2,3,22}$.

El doctor Eduardo Calderón Paul, jefe del Instituto de Anatomía Patológica del antiguo Hospital San José, al rendir un homenaje a. la memoria del doctor Ricardo Dávila Boza, el 2 de diciembre de 1950, subrayó: "de suyo brusco y bondadoso, Ricardo Dávila Boza, tenía sus convicciones claras y definidas. Nunca vaciló en salir a la palestra en defensa de sus ideas o atacando las contrarias de acuerdo al lema: las ideas se combaten con ideas. En esto fue cáustico y mordaz. No hay duda que esta característica lo perjudicó en una carrera donde pudo alcanzar mejor situación dadas sus relevantes condiciones intelectuales, pero su carácter era asi y no admitía componendas"3.

Junto con los doctores José Joaquín Aguirre, Alejandro del Río, Federico Fuga Borne, Octavio Maira, Pedro Lautaro Ferrer, el doctor Ricardo Dávila Boza formó parte de los principales médicos que colaboraron con la Salud Pública desde la perspectiva de la Higiene, entre 1870 y $1910^{23}$.

El doctor Dávila Boza falleció en Santiago el 17 de junio de $1937^{1}$.

\section{Resumen}

El doctor Ricardo Dávila Boza (1850 -1937) fue un hombre de personalidad sin dobleces, "brusco $y$ bondadoso, de convicciones claras y definidas". Dotado de una visión luminosa e incansable tenacidad; de pluma fácil, publicó numerosísimos trabajos de todo orden: científico, literario y poético. Siempre dispuesto a defender sus ideas, respetando las contrarias con gran hidalguía y sin permitir componendas. En esta comunicación se destaca su labor en los Hospitales San José y San Juan de Dios de Santiago, preocupándose del estudio de la clínica y epidemiología de las enfermedades infecciosas, transformándose al cabo de algunos años en ilustre higienista y salubrista, siendo parte de un selecto grupo de médicos que colaboraron con la Salud Pública, desde aquella contingencia, entre 1870 y 1910. Durante 21 años fue Director del antiguo Instituto de Higiene Pública. Importante fue la labor inteligente y sagaz del doctor Dávila Boza durante las epidemias de peste bubónica y viruela, acontecidas en el país, en la segunda mitad del siglo 19 y primeros años del 20, mencionándose además su inquietud por los problemas de la patología infantil. Nacido en La Serena, volvió al norte de su patria a Freirina y Copiapó, para iniciar el ejercicio profesional. 


\section{Referencias}

1.- Laval M E. Noticias sobre los médicos en Chile. Siglo XIX (C-D-E). Ed. Historia Médica. Santiago de Chile 1972; 2: 177-85.

2.- Figueroa V. Diccionario histórico, biográfico y bibliográfico de Chile. 1800-1925, Santiago de Chile. Ed. Balcells. p. $540-1$.

3.- Calderón P E. Homenaje al doctor Ricardo Dávila Boza. 2 de diciembre de 1950. (Inédito).

4.- Dávila B R. Rev Médica de Freirina durante el año 1877. Rev Méd Chile 1877-1878; 6: 289-92.

5.- Dávila B R. Rev Médica de Copiapó durante al año 1879. Rev Méd Chile 1879-1880; 8: 284-6.

6.- Aguirre C J J, Puelma T F. Exhumaciones de cadáveres y ceremonias de cuerpo presente. Rev Méd Chile 1883; 11: 135-40.

7.- Dávila B R. Los cadáveres considerados desde el punto de vista higiénico y social. La
Lectura. 1884, p.226, 233, 242, 250, 257 y 339. 1885, p 176. Santiago de Chile.

8.- Laval M E. Los primeros 40 años del Hospital San José de Santiago. (Inédito).

9.- Bascuñán G M. Hospital San José. (En Chile en 1908 de Eduardo Poirier. Impta. Barcelona. 1909, p. 200.

10.- Laval M E. Historia del Hospital San Juan de Dios de Santiago. Impta. Stanley. 1949. Santiago de Chile.

11.- Laval M E, García V R. Síntesis del desarro1lo histórico de la Salubridad en Chile. Rev SNS 1956; 1: 23-33.

12.- Dávila B R. Higiene Pública en Chile. En Chile en 1908 de Eduardo Poirier. Impta. Barcelona. 1909. p.180-197.

13.- Del Río A, Zegers R, Dávila B R, Montero L. Informe sobre la epidemia de peste bubónica en Iquique en 1903 presentada al Supremo Gobierno por la comisión de reconocer la naturaleza de la enfermedad y organizar su profilaxis. Rev Chil Hig 1903; 9: 1-194.

14.- Dávila B R. La peste bubónica en 1903-
1904. Rev Chil Hig 1905; 11: 208-43.

15.- Dávila B R. La peste bubónica en Chile. Rev Chil Hig 1910; 16: 183-94.

16.- Dávila B R. Informe sobre ubicación de un Lazareto para pestosos en Santiago. Rev Chil Hig 1903; 9: 386.

17.- Dávila B R. Situación sanitaria del país. Rev Chil Hig 1915; 21: 105-26.

18.- Dávila B R. La viruela. Rev Méd Chile 1893; 21: 81-7.

19.- Dávila B R. Viruela. Epidemia de 1902 a 1904. Rev Chil Hig 1905; 11: 109-207.

20.- Dávila B R. Obra de hermandad y de verdadero patriotismo.

Rev Méd Chile 1893; 21: 409-11.

21.- Dávila B R. Mercedes (novela). Rev de Artes y Letras 1887, p. 481, 561.

22.- Eliz L. Siluetas líricas y’ biográficas sobre los más distinguidos poetas nacionales, p.447 (apéndice). Imprenta de la Unión. Santiago de Chile. 1880.

23.- Portal de la Cultura de Chile. Memoria, chilena. Higiene y Salud Pública en Chile. (1870-1910). 2004. 